\title{
A combinational approach to realize highly efficient light-emitting electrochemical cells
}

Rong-Huei Yi, ${ }^{a+}$ Chieh-Liang Lo, ${ }^{\mathrm{b}+}$ Dian Luo, ${ }^{\mathrm{b}}$ Chien-Hsiang Lin, ${ }^{\mathrm{a}}$ Shu-Wen Weng, ${ }^{\mathrm{c}}$ Chin-Wei Lu, ${ }^{\mathrm{a}, *}$ Shun-Wei Liu, ${ }^{\mathrm{d}}$ Chih-Hao Chang ${ }^{\mathrm{c}}$ and Hai-Ching Su${ }^{\mathrm{b}, *}$

${ }^{a}$ Department of Applied Chemistry, Providence University, Taichung 43301, Taiwan

${ }^{\mathrm{b}}$ Institute of Lighting and Energy Photonics, National Chiao Tung University, Tainan 71150, Taiwan

${ }^{\mathrm{c}}$ Department of Photonics Engineering, Yuan Ze University, Chung-Li 32003, Taiwan

d Department of Electronic Engineering, Ming Chi University of Technology, New Taipei City 24301, Taiwan

${ }^{+}$Equal contribution

\section{Corresponding Authors}

E-mail: cwlu@pu.edu.tw; Fax: 886-4-26327554; Tel: 886-4-26328001-15213 (Chin-Wei Lu)

E-mail: haichingsu@mail.nctu.edu.tw; Fax: 886-6-3032535; Tel: 886-6-3032121-57792 (Hai-Ching $\mathrm{Su})$ 


\section{Contents}

1. ${ }^{1} \mathrm{H},{ }^{13} \mathrm{C}$ and ${ }^{1} \mathrm{H}-{ }^{1} \mathrm{H}$ COSY NMR spectra $\quad$ S3

2. Mass spectrum $\quad$ S4

3. Theoretical calculation $\quad$ S5

4. Thermogravimetric analysis $\quad$ S6

5. Excited-state lifetime analysis $\quad$ S6

$\begin{array}{ll}\text { 6. Structure of related complex BG for reference } & \text { S7 }\end{array}$

7. PL spectra of the emissive layers of host-guest LECs $\quad$ S7

8. Refractive index spectra of the emissive layers of the LECs S8

9. EL characteristics of the thick host-guest LECs $(490 \mathrm{~nm})$ without and with diffusive layers S9 


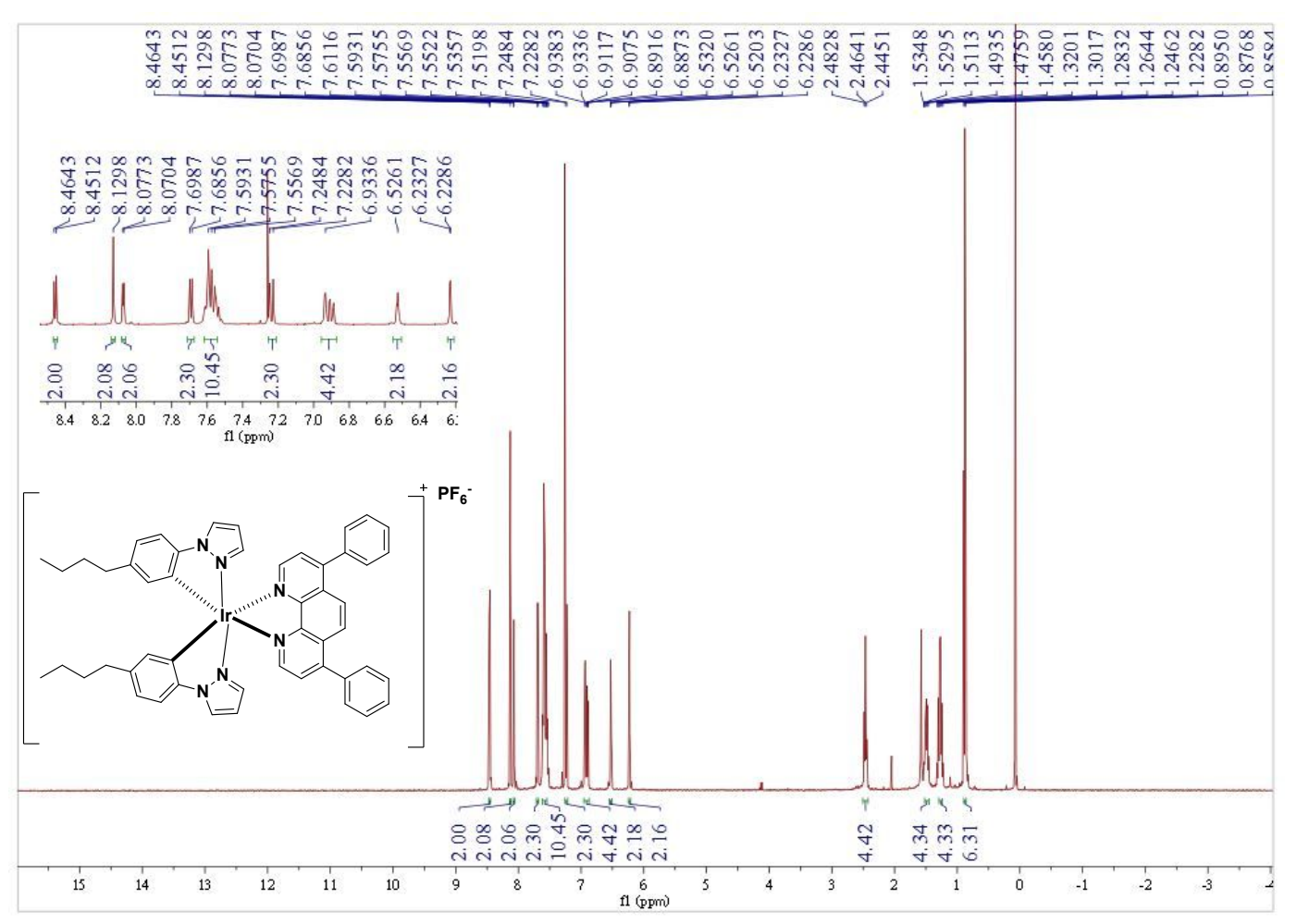

Figure. S1 ${ }^{1} \mathrm{H}$ NMR spectrum for complex $\mathbf{Y I r}\left(400 \mathrm{MHz}, \mathrm{CDCl}_{3}, 298 \mathrm{~K}\right)$. 


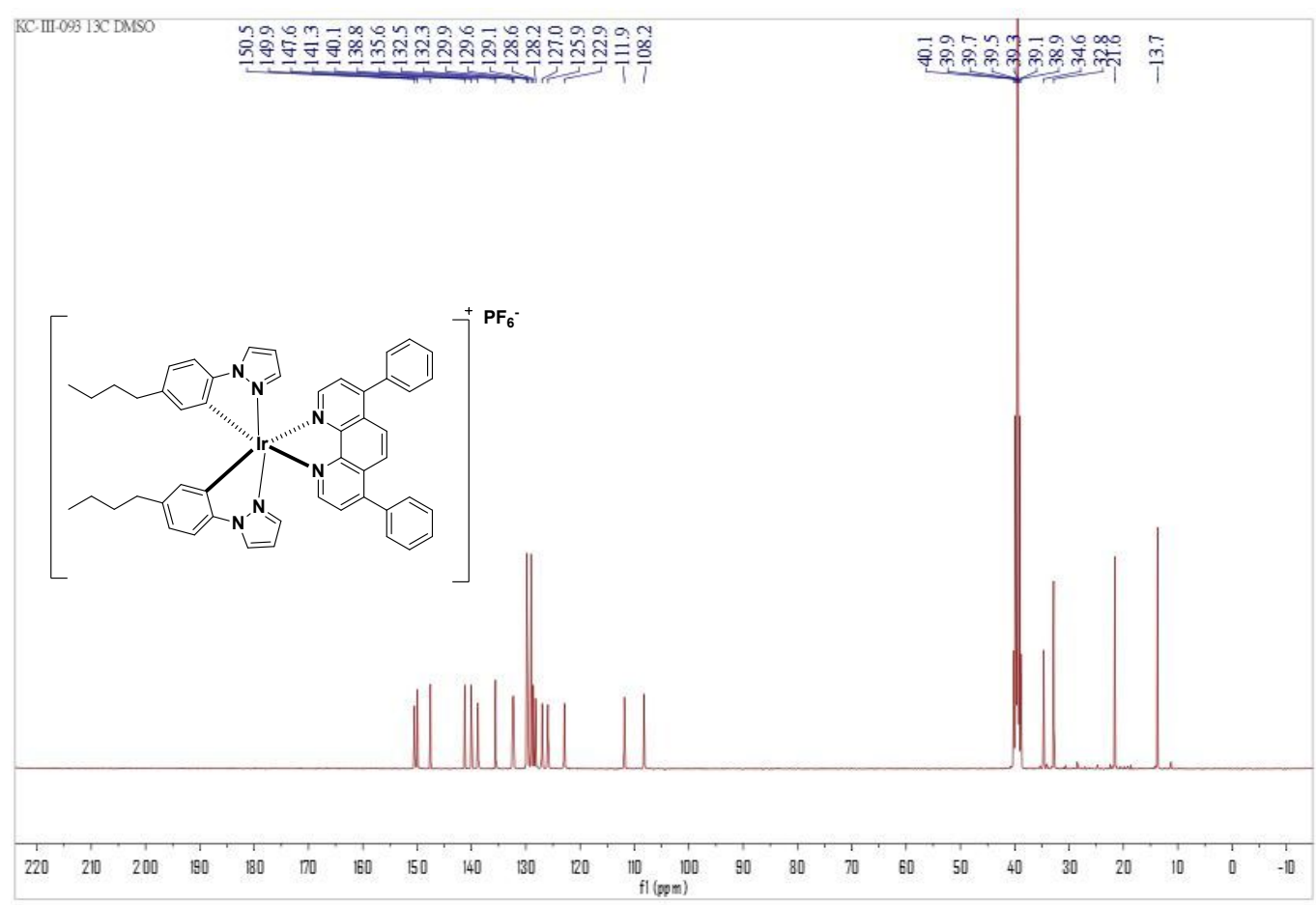

Figure. S2 ${ }^{13} \mathrm{C}$ NMR spectrum for complex $\operatorname{YIr}\left(100 \mathrm{MHz}, \mathrm{CDCl}_{3}, 298 \mathrm{~K}\right)$.

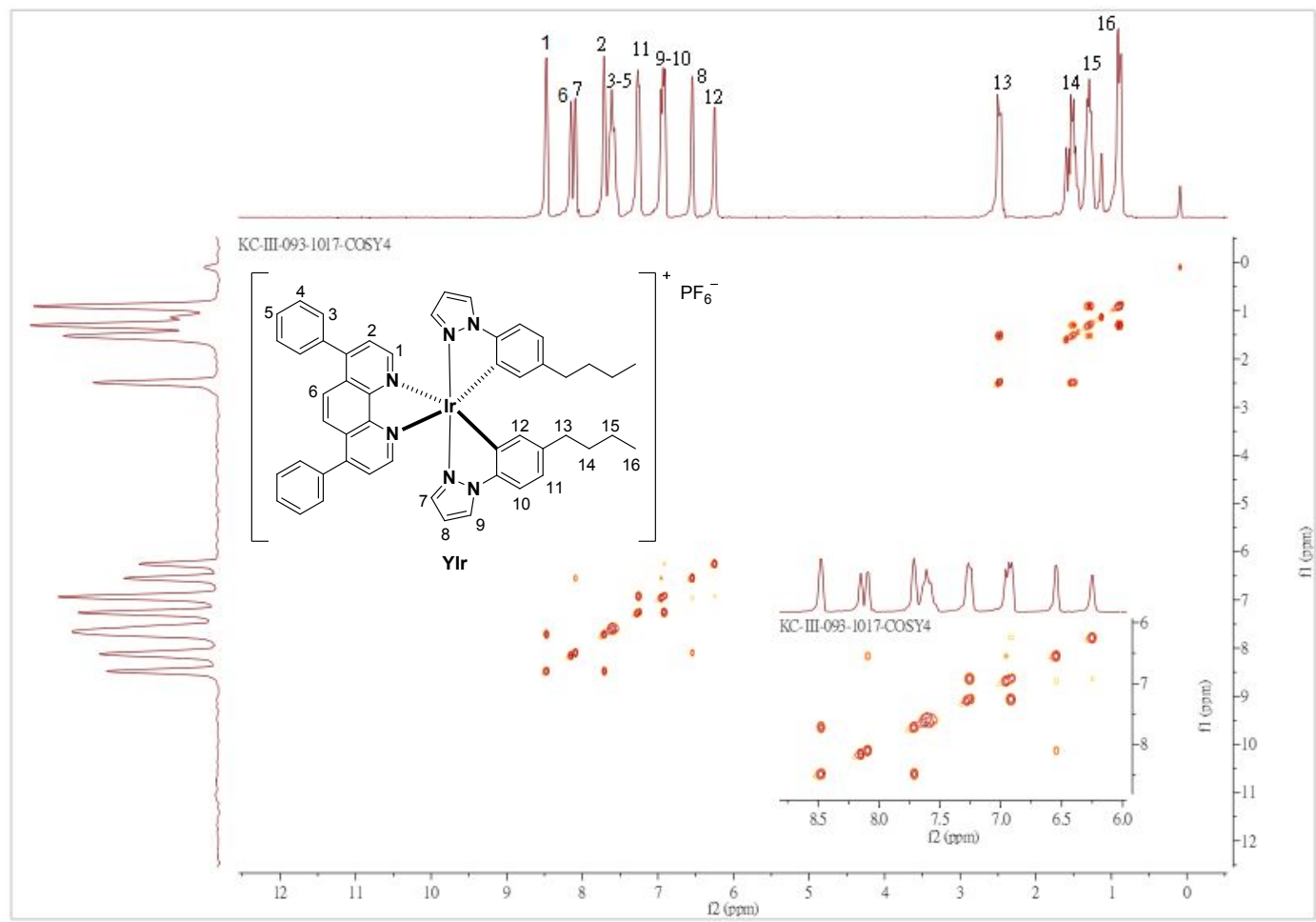

Figure. S3 ${ }^{1} \mathrm{H}-{ }^{1} \mathrm{H}$ COSY spectrum $\left(400 \mathrm{MHz}\right.$, pulse width of $14.0 \mu \mathrm{s}$ ) of complex YIr in $\mathrm{CDCl}_{3}$ at $298 \mathrm{~K}$, the inset is the expansion of the aromatic region. 


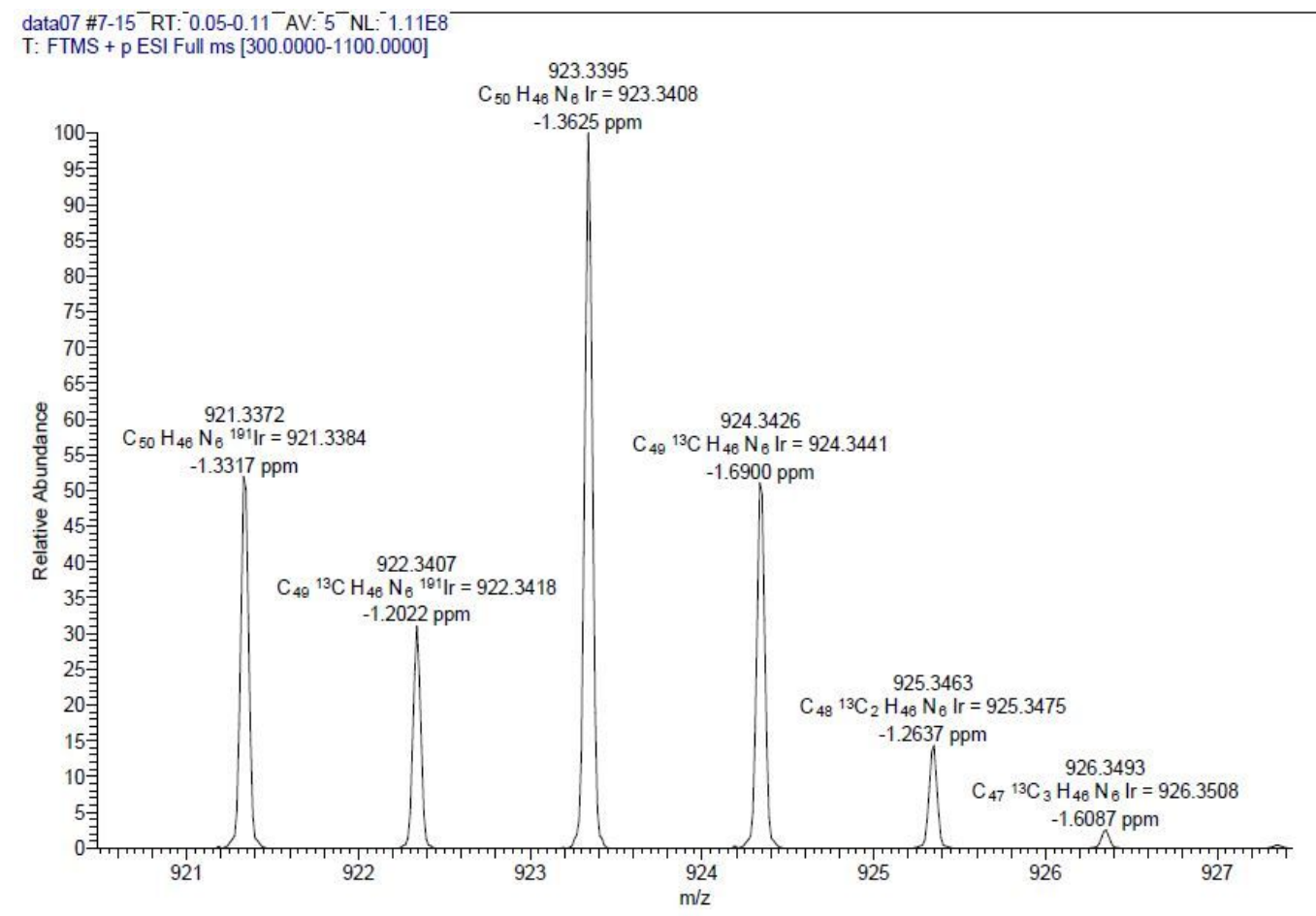

Figure. S4 HRMS-ESI ${ }^{+}$spectrum of complex YIr.

Table. S1 Calculated singlet and triplet states for complex YIr by TD-DFT approach.

\begin{tabular}{cccccc}
\hline Complex & States & $\begin{array}{c}\mathbf{e V}^{[\mathbf{a}]} \\
\left(\lambda_{\text {cal }}, \mathbf{n m}\right)\end{array}$ & $\boldsymbol{f}$ & $\begin{array}{c}\text { Dominant } \\
\text { excitations }\end{array}$ & $\begin{array}{c}\text { Ground state } \\
\text { dipole moment } \\
\text { (D) }\end{array}$ \\
\hline YIr & $\mathrm{S}_{1}$ & $2.33(532)$ & 0.4488 & $\mathrm{H} \rightarrow \mathrm{L}(49 \%)$ & \\
& $\mathrm{S}_{2}$ & $2.55(486)$ & 0.1850 & $\mathrm{H} \rightarrow \mathrm{L}+1(49 \%)$ & \\
& & & $\mathrm{H}-5 \rightarrow \mathrm{L}(1 \%)$ & \\
& $\mathrm{T}_{1}$ & $1.71(726)$ & 0.0000 & $\mathrm{H}-2 \rightarrow \mathrm{L}(2 \%)$ & \\
& & & $\mathrm{H} \rightarrow \mathrm{L}(43 \%)$ & \\
\hline
\end{tabular}

[a] Calculated excitation energies for the singlet states in MeCN solution. [b] H and L denote the HOMO and LUMO, respectively; data in parentheses are the contributions of the excitation; for $\mathrm{S}_{1}$ states, all excitations are presented, only the dominant excitation are presented. 


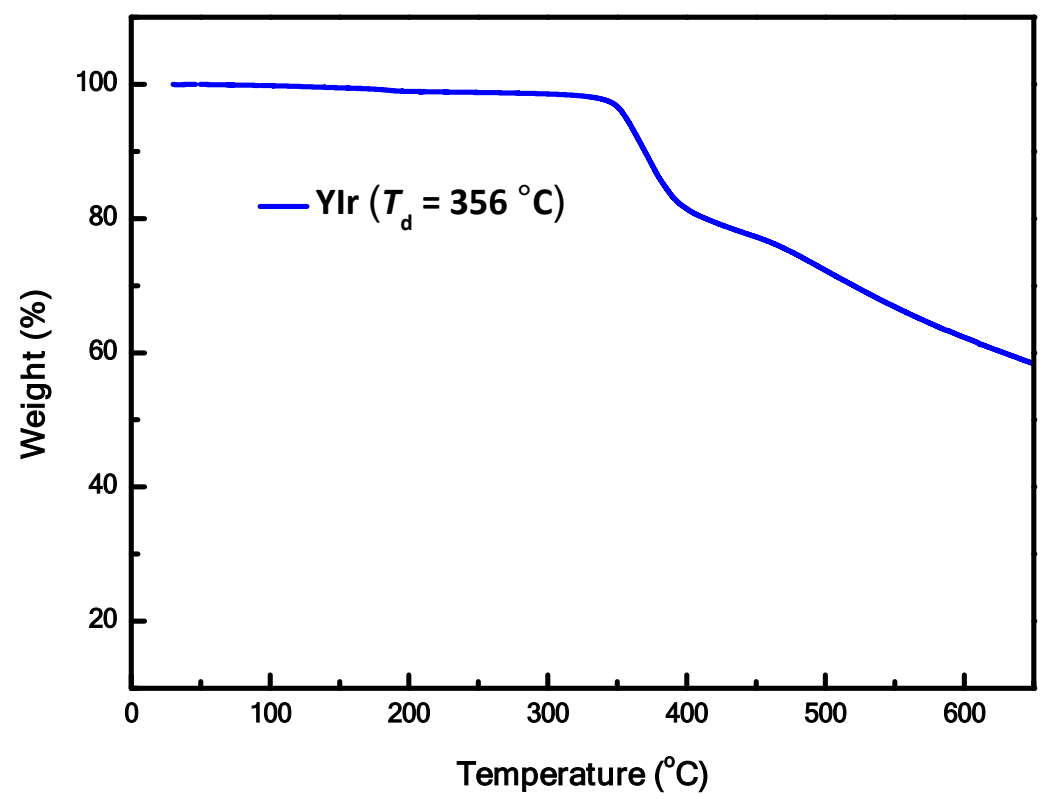

Figure. S5 TGA data of complex YIr under $\mathrm{N}_{2}$ atmosphere at a heating rate of $10{ }^{\circ} \mathrm{C} \mathrm{min}^{-1}$.

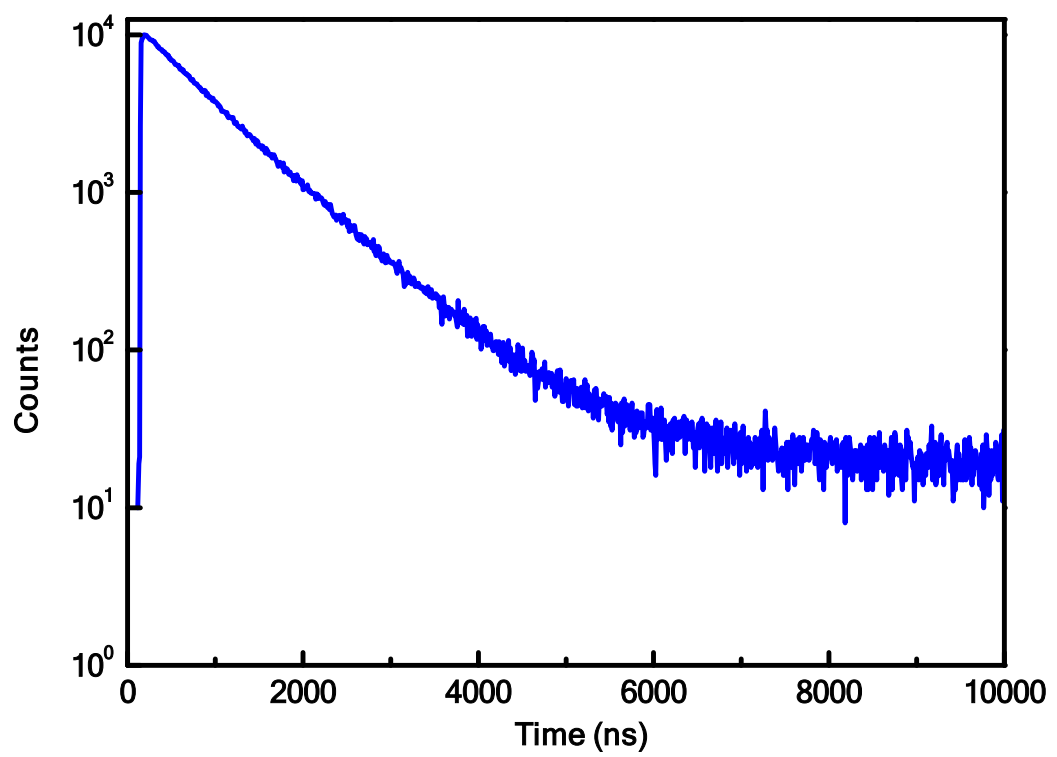

Figure. S6 Phosphorescence decay of cationic iridium complex YIr. 


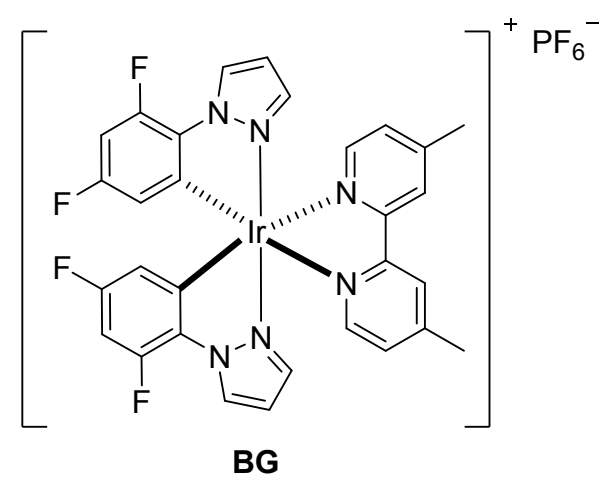

Figure. S7 Structure of related complex BG for reference.

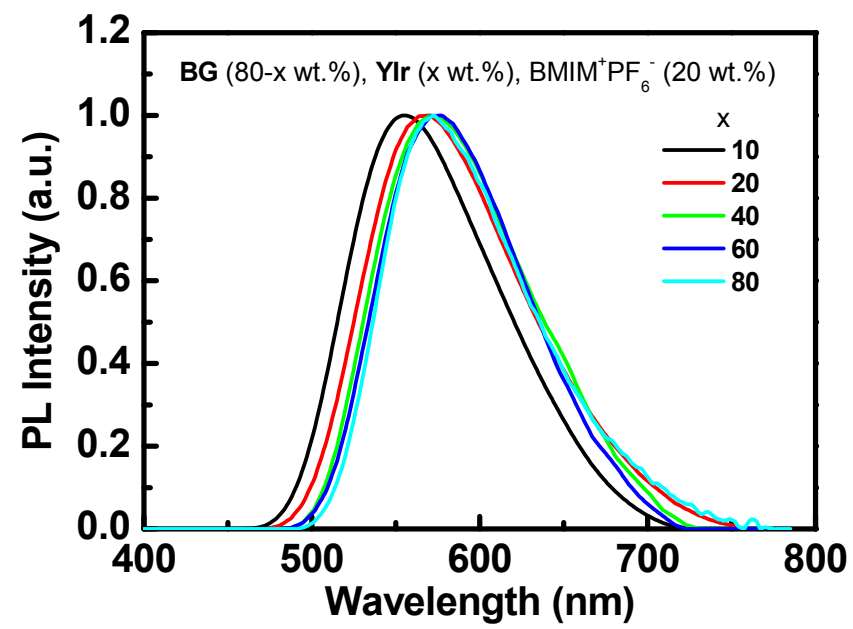

Figure. S8 PL spectra of the host-guest emissive layers based on the host complex BG doped with the guest complex Yir. 


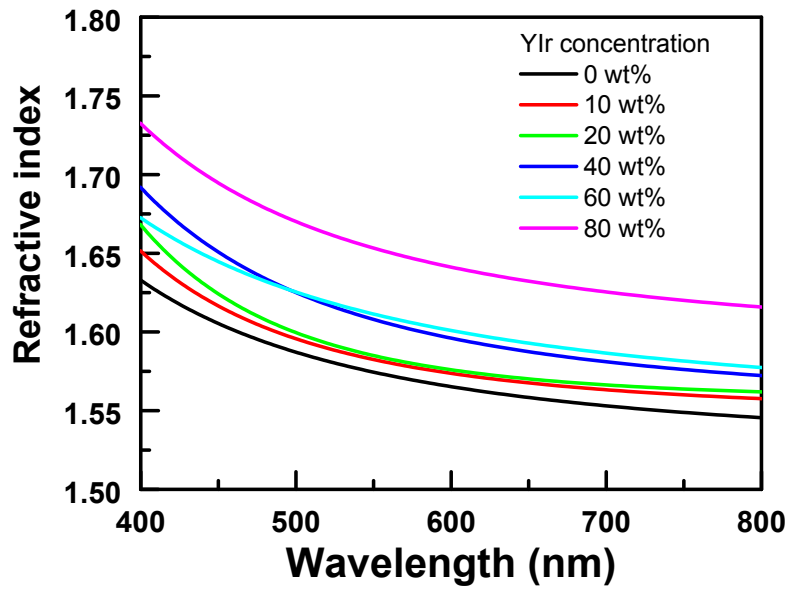

Figure. S9 Refractive index spectra of the emissive layers of the LECs. 
(a)

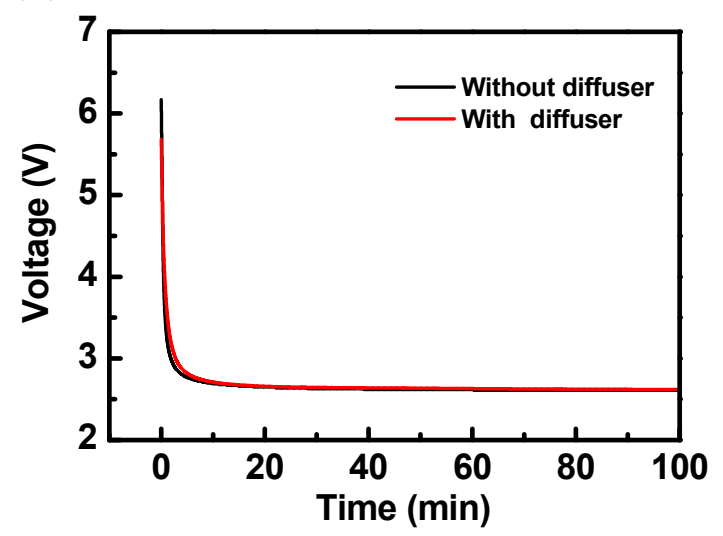

(b)

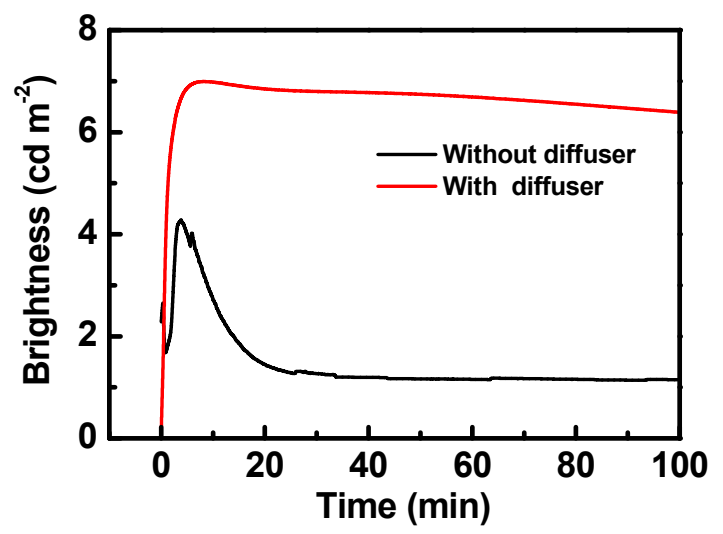

(c)

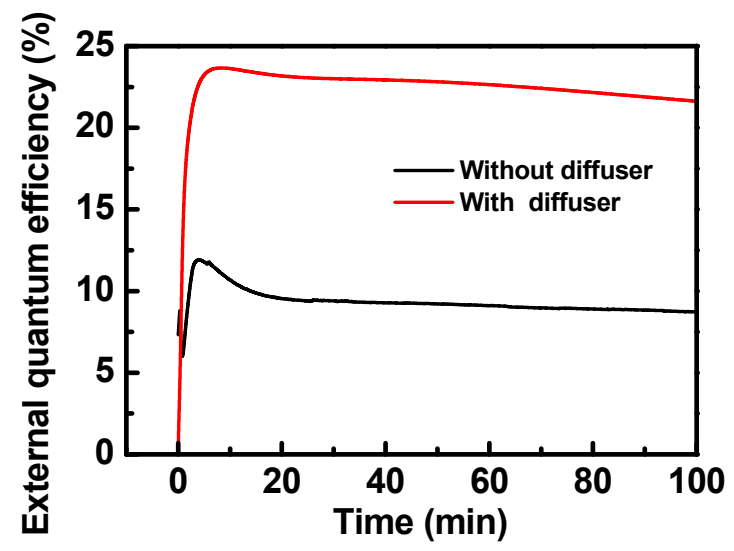

Figure. S10 Time-dependent a) voltage, b) brightness and c) EQE of the thick host-guest LECs (490 nm) based on complex BG doped with 20 wt.\% complex YIr under $0.1 \mu \mathrm{A}$ without (black line) and with diffusive layer (red line). 